\title{
Synthesis of Difluorinated Enynes through Sonogashira-Type Coupling
}

\section{Takumi Fujino, Tomoaki Hinoue, Yoshinosuke Usuki, Tetsuya Satoh}

\begin{tabular}{|c|l|}
\hline Citation & Organic Letters, 18 (21): 5688-5691 \\
\hline Issue Date & $2016-10-17$ \\
\hline Type & Journal Article \\
\hline Textversion & Author \\
\hline Rights & $\begin{array}{l}\text { This document is the Accepted Manuscript version of a Published Work that appeared } \\
\text { in final form in Organic Letters, copyright C American Chemical Society after peer } \\
\text { review and technical editing by the publisher. To access the final edited and published } \\
\text { work see https://doi.org/10.1021/acs.orglett.6b02919 }\end{array}$ \\
\hline $\begin{array}{c}\text { Supporting } \\
\text { Information }\end{array}$ & $\begin{array}{l}\text { The Supporting Information is available free of charge on the ACS Publications } \\
\text { website at https://doi.org/10.1021/acs.orglett.6b02919. }\end{array}$ \\
\hline DOI & \begin{tabular}{l} 
10.1021/acs.orglett.6b02919 \\
\hline
\end{tabular}
\end{tabular}

Self-Archiving by Author(s)

Placed on: Osaka City University

Takumi Fujino, Tomoaki Hinoue, Yoshinosuke Usuki, Tetsuya Satoh. (2016). Synthesis of Difluorinated Enynes through Sonogashira-Type Coupling. Organic Letters. 18, 5688-5691. Doi:

10.1021/acs.orglett.6b02919 


\title{
Synthesis of Difluorinated Enynes through Sonogashira-type Coupling
}

\author{
Takumi Fujino, Tomoaki Hinoue, Yoshinosuke Usuki, and Tetsuya Satoh* \\ Department of Chemistry, Graduate School of Science, Osaka City University, 3-3-138 Sugimoto, Sumiyoshi-ku, Osaka \\ 558-8585, Japan \\ satoh@sci.osaka-cu.ac.jp
}

Supporting Information Placeholder

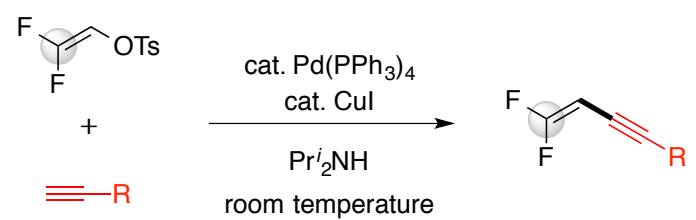

\begin{abstract}
The Sonogashira-type coupling of 2,2-difluoroethenyl tosylate with a variety of aliphatic and aromatic terminal alkynes proceeds smoothly even at room temperature to produce the corresponding difluorinated enyne derivatives. 2,2Difluoroethenyl tosylate is a useful difluoroethenyl source because of its ready availability from 2,2,2-trifluoroethanol. Some of obtained enynes exhibits strong fluorescence in the solid state. Further derivatization of a difluorinated enyne through Rh(III)catalyzed oxidative coupling has also been examined.
\end{abstract}

gem-Difluoroalkenyl units can be seen in a variety of biologically active compounds and their synthetic intermediates. ${ }^{1}$ Recently, $\pi$-conjugated molecules containing gemdifluoroalkenyl functions have attracted attention because of their optical and electrochemical properties. ${ }^{2}$ Therefore, development of synthetic methods for introducing the gemdifluoroalkenyl groups on organic molecules regioselectively under mild conditions has been desired. The cross-coupling reactions of 2,2-difluoroethenyl tosylate appear to be promising approaches toward such functionalized $\pi$-conjugated molecules, because the tosylate is readily available even in high-volume from 2,2,2-trifluoroethanol (TFE) (Scheme 1), ${ }^{3}$ which has become widely employed as a solvent in organic chemistry laboratories. However, the utilization of the tosylate in cross-coupling reactions has been limited to only Suzuki-Miyaura coupling. ${ }^{4,5}$ In the context of our studies on the synthesis of fluorine-containing functionalized molecules, ${ }^{6}$ we have found that the tosylate also undergoes Sonogashiratype coupling ${ }^{7}$ upon treatment with terminal alkynes in the presence of a palladium-copper catalyst system to produce difluorinated enyne derivatives selectively. ${ }^{8}$ In contrast to the previous Suzuki-Miyaura coupling, ${ }^{4}$ the present reaction proceeds efficiently even at room temperature and without any alkylphosphine ligands. Notably, some of obtained enynes exhibit solid-state fluorescence. Further derivatization of the difluorinated enyne has also been examined. These new findings are described herein.
Scheme 1. Preparation and Cross-Coupling of 2,2Difluoroethenyl Tosylate

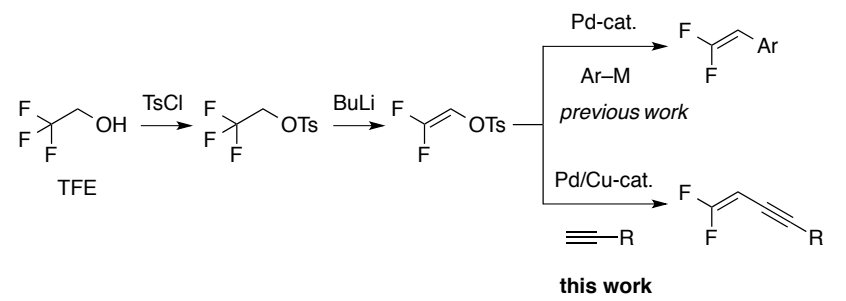

In an initial attempt, 2,2-difluoroethenyl tosylate (1) (0.25 mmol) was treated with 1-hexadecyne (2a) $(0.25 \mathrm{mmol})$ in the presence of $\mathrm{Pd}\left(\mathrm{PPh}_{3}\right)_{4}(0.013 \mathrm{mmol})$ and $\mathrm{CuI}(0.038$ mmol) as catalysts under argon in $\operatorname{Pr}_{2}^{i} \mathrm{NH} / \mathrm{THF}(1: 1)$ at $85^{\circ} \mathrm{C}$ for $1 \mathrm{~h}$. As expected, Sonogashira-type coupling took place to produce 1,1-difluorooctadec-1-en-3-yne (3a) in 69\% yield (entry 1 in Table 1). Increasing the amount of $\mathbf{2 a}$ to 0.38 mmol somewhat improved the yield of $\mathbf{3 a}$ to $75 \%$ (entry 2 ). While reducing the amount of $\mathrm{CuI}$ by half did not affect the reaction efficiency significantly (entry 3), the yield of 3a markedly decreased to $30 \%$ in the absence of $\mathrm{CuI}$ (entry 4 ). It should be noted that the reaction could be conducted efficiently under milder conditions. Even at room temperature, 3a was obtained in $80 \%$ yield by extending the reaction time to $2 \mathrm{~h}$ (entry 6). 
Table 1. Reaction of 2,2-Difluoroethenyl Tosylate (1) with 1-Hexadecyne (2a) ${ }^{a}$

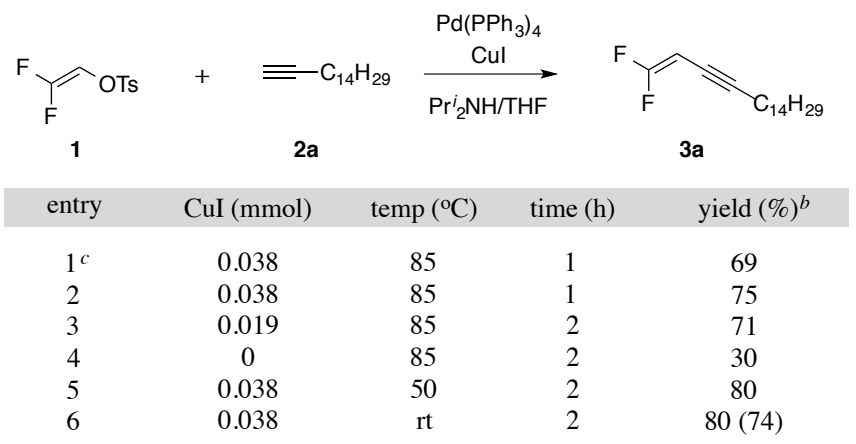

${ }^{a}$ Reaction conditions: $\mathbf{1}(0.25 \mathrm{mmol}), \mathbf{2 a}(0.38 \mathrm{mmol}), \mathrm{Pd}\left(\mathrm{PPh}_{3}\right)_{4}$ $(0.013 \mathrm{mmol})$ in $\operatorname{Pr}_{2}^{i} \mathrm{NH} / \mathrm{THF}(1: 1,2 \mathrm{~mL})$ under Ar, unless otherwise noted. ${ }^{b}$ GC yield based on the amount of 1a used. Value in parentheses indicates yield after purification. ${ }^{c}$ With $2 \mathrm{a}(0.25$ $\mathrm{mmol})$.

We next examined the reactions of a variety of terminal alkynes 2 with tosylate 1 under the conditions used in entry 6 of Table 1 (Table 2). The reactions using linear aliphatic alkynes, 1-pentadecyne (2b) and 1-dodecyne (2c), in place of 2a proceeded efficiently to produce the corresponding enynes $\mathbf{3 b}$ and $\mathbf{3 c}$ in 76 and $74 \%$ yields, respectively, within $2 \mathrm{~h}$. Oct-7-yn-1-ol (2d) and 1,1-diphenylprop-2-yn-1-ol (2e) underwent the coupling with $\mathbf{1}$ to give enynes $\mathbf{3 d}$ and $\mathbf{3 e}$, showing the tolerance of hydroxy groups. For the present coupling, a series of aromatic alkynes can also be employed. Thus, in addition to unsubstituted phenylacetylene (2f), 4-methoxyl (2g), -phenyl (2h), -chloro (2i), and -bromo (2j) substituted phenylacetylenes coupled with $\mathbf{1}$ to afford $\mathbf{3 f}-\mathbf{j}$ in $39-68 \%$ yields. Electron deficient substrates tend to need longer reaction times and afford lower yields. Besides these phenylacetylenes, 2-naphthyl (2k), 9-anthryl (2l), and 9-phenanthryl (2m) acetylenes reacted with $\mathbf{1}$ in a similar manner to produce $3 \mathbf{k}-\mathbf{m}$ in $47-82 \%$ yields.

The rather high yield preparation of enyne $\mathbf{3 f}$ was achieved by decarboxylative coupling ${ }^{9}$ of readily available phenylpropiolic acid (4) with 1. Thus, treatment of $1(0.25$ mmol) with $4(0.38 \mathrm{mmol})$ in the presence of $\mathrm{Pd}\left(\mathrm{PPh}_{3}\right)_{4}$ $(0.013 \mathrm{mmol})$ and $\mathrm{CuI}(0.038 \mathrm{mmol})$ under argon in $\mathrm{Pr}_{2}^{i} \mathrm{NH} / \mathrm{THF}(1: 1)$ at room temperature for $2 \mathrm{~h}$ gave $\mathbf{3 f}$ in $74 \%$ yield (Scheme 2 ). Since a series of arylpropiolic acids can be easily prepared through Sonogashira coupling of aryl halides with propiolic acid itself without bothersome protection/deprotection processes, ${ }^{9 a}$ the decarboxylative coupling provides a powerful alternative for preparation of difluorinated enynes.

Scheme 2. Decarboxylative Coupling of Phenylpropiolic Acid (4) with 2,2-Difluoroethenyl Tosylate (1)

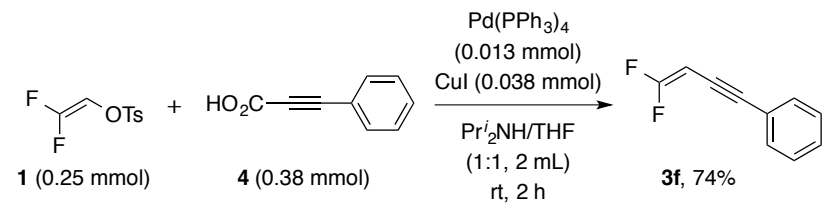

Table 2. Reaction of 2,2-Difluoroethenyl Tosylate (1) with Alkynes $2^{a}$

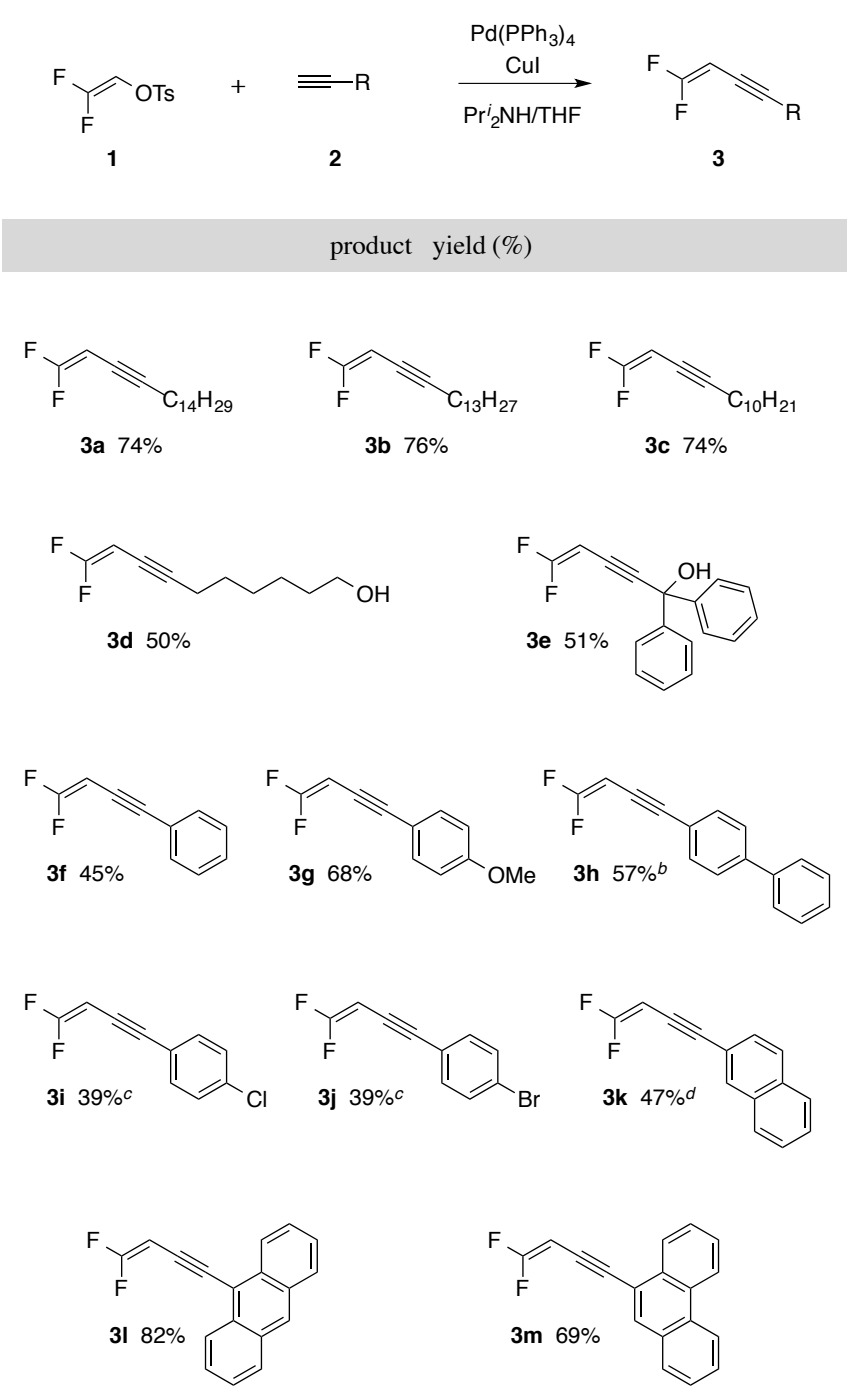

a Reaction conditions: 1 (0.25 mmol), 2 (0.38 mmol), $\mathrm{Pd}\left(\mathrm{PPh}_{3}\right)_{4}(0.013 \mathrm{mmol}), \mathrm{CuI}(0.038 \mathrm{mmol})$ in $\operatorname{Pr}_{2}^{i} \mathrm{NH} / \mathrm{THF}$ $(1: 1,2 \mathrm{~mL})$ under Ar at rt for 2 h. ${ }^{b}$ For 6 h. ${ }^{c}$ For 8 h. ${ }^{d}$ For 5 $\mathrm{h}$.

Finally, we conducted preliminary investigations on the properties and applications of newly prepared difluorinated enynes. Anthryl-substituted enyne 31 showed strong fluorescence in the solid state at $485 \mathrm{~nm}$ (excited at $365 \mathrm{~nm}$ ) (Figure 1). The largely red-shifted fluorescence compared with that in the liquid state $(417 \mathrm{~nm})$ is attributed to the $\pi$-stacked structure of $\mathbf{3 l}$ in the solid state (for single crystal and crystal packing structures, see the Supporting Information). The quantum efficiency of the solid-state fluorescence was determined to be an absolute value of 0.35 . 


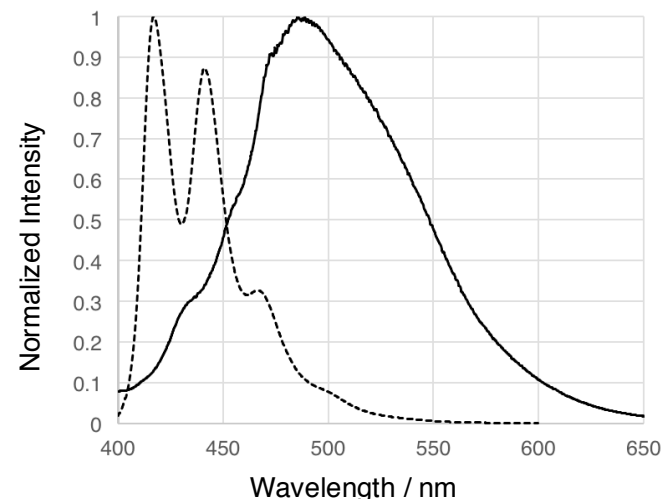

Figure 1. Normalized photoluminescence spectra (excited at $365 \mathrm{~nm})$ of $3 \mathrm{I}$ in hexane solution $\left(1.0 \times 10^{-5} \mathrm{M}\right)$ (dotted line) and solid state (solid line).

In addition, difluorinated enynes can be building blocks in construction for more structurally complicated $\pi$-conjugated molecules through further coupling reactions. For example, we and other groups have developed the rhodium(III)catalyzed oxidative coupling reactions of various aromatic substrates with alkynes via regioselective $\mathrm{C}-\mathrm{H}$ bond cleavage to form annulated products. ${ }^{10,11}$ Expectedly, enyne $\mathbf{3 h}$ was found to undergo this kind of oxidative coupling with $\mathrm{N}$ acetylaniline (5). ${ }^{12}$ Although the reaction conditions have not been optimized yet, a difluoroethenyl-substituted indole derivative 6 was obtained in a moderate yield (Scheme 3 ). It has been reported that this type of gemdifluoroethenyl(hetero)arenes can be readily transformed to $\beta, \beta, \beta$-trifluoroethyl(hetero)arenes upon treatment with TBAF. ${ }^{13}$ A range of $\beta, \beta, \beta$-trifluoroethyl(hetero)arenes including 3-( $\beta, \beta, \beta$-trifluoroethyl)indoles have been known to show unique biological activities. ${ }^{14}$

\section{Scheme 3. Rh(III)-Catalyzed Oxidative Coupling of Enyne 3h with $N$-Acetylaniline (5)}

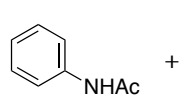

$5(0.2 \mathrm{mmol})$

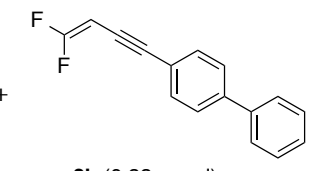

$3 \mathrm{~h}(0.22 \mathrm{mmol})$

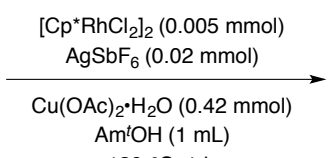

$120^{\circ} \mathrm{C}, 1 \mathrm{~h}$

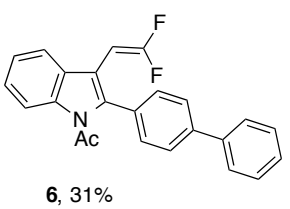

In summary, we have demonstrated that the synthesis of difluorinated enynes can be achieved through the palladiumcatalyzed coupling of 2,2-difluoroethenyl tosylate with terminal alkynes. The tosylate is readily preparable even in high-volume from an organic solvent, 2,2,2-trifluoroethanol. Moreover, the synthesized enynes are expected to undergo further coupling with various aromatic substrates. Therefore, the reaction sequence provides cost-effective, simple synthetic routes toward fluorinated $\pi$-conjugated molecules. Work is underway toward the further development of the procedures.

\section{ASSOCIATED CONTENT}

\section{Supporting Information}

The Supporting Information is available free of charge on the ACS Publications website at DOI: 10.1021/acs.orglett.

Experimental procedures and characterization data of products (PDF)

Crystallographic data for $\mathbf{3 l}$ and $\mathbf{6}(\mathrm{CIF})$

\section{AUTHOR INFORMATION}

\section{Corresponding Authors}

*E-mail: satoh@sci.osaka-cu.ac.jp

\section{Author Contributions}

All authors have given approval to the final version of the manuscript.

Notes

The authors declare no competing financial interest.

\section{ACKNOWLEDGMENT}

This work was partly supported by JSPS KAKENHI Grant Number JP16H01037 in Precisely Designed Catalysts with Customized Scaffolding, JST (ACT-C), and NEDO, Japan.

\section{REFERENCES}

(1) For example, see: (a) Dai, W.; Zhang, X.; Zhang, J.; Lin, Y.; Cao, S. Adv. Synth. Catal. 2016, 358, 183. (b) McAlpine, I.; TranDubé, M.; Wang, F.; Scales, S.; Matthews, J.; Collins, M. R.; Nair, S. K.; Nguyen, M.; Bian, J.; Alsina, L. M.; Sun, J.; Zhong, J.; Warmus, J. S.; O’Neill, B. T. J. Org. Chem. 2015, 80, 7266, (c) Jang, E. B.; Khrimian, A.; Siderhurst, M. S. J. Chem. Ecol. 2011, 37, 553. (d) Nguyen, T. B.; Martel, A.; Dhal, R.; Dujardin, G. Synlett 2009, 2492. (e) Madden, B. A.; Prestwich, G. D. Bioorg. Med. Chem. Lett. 1997, 7, 309. (f) Moore, W. R.; Schatzman, G. L.; Jarvi, E. T.; Gross, R. S.; McCarthy, J. R. J. Am. Chem. Soc. 1992, 114, 360. (g) Bobek, M.; Kavai, I.; De Clercq, E. J. Med. Chem. 1987, 30, 1494.

(2) For recent examples, see: (a) da Silva, F. F.; Almeida, D.; Vasekova, E.; Drage, E.; Mason, N. J.; Limao-Vieira, P. Chem. Phys. Lett. 2012, 550, 62. (b) Alkorta, I.; Blanco, F.; Elguero, J. J. Phys. Org. Chem. 2008, 21, 381. (c) Akkerman, F. A.; Kickbusch, R.; Lentz, D. Chem. Asian J. 2008, 3, 719. (d) Ottosson, H.; Kilsa, K.; Chajara, K.; Piqueras, M. C.; Crespo, R.; Kato, H.; Muthas, D. Chem. Eur. J. 2007, 13, 6998 .

(3) (a) Ichikawa, J.; Wada, Y.; Fujiwara, M.; Sakoda, K. Synthesis 2002, 1917. (b) Ichikawa, J.; Fujiwara, M.; Nawata, H.; Okauchi, T.; Minami, T. Tetrahedron Lett. 1996, 8799.

(4) Gøgsig, T. M.; Søbjerg, L. S.; Lindhardt, A. T.; Jensen, K. L.; Skrydstrup, T. J. Org. Chem. 2008, 73, 3404.

(5) Cross-coupling reactions using 2,2-difluoroethenylmetal reagents prepared from 2,2-difluoroethenyl tosylate have been reported. For a review, see: Ichikawa, J. J. Fluorine Chem. 2000, 105, 257.

(6) (a) Usuki, Y.; Wakamatsu, Y.; Yabu, M.; Iio, H. Asian J. Org. Chem. 2014, 3, 1270. (b) Hayashi, T.; Usuki, Y.; Wakamatsu, Y.; Iio, H. Synlett 2010, 2843. (c) Hayashi, T.; Usuki, Y.; Iio, H. J. Fluorine Chem. 2010, 131, 709 .

(7) (a) Sonogashira, K.; Tohda, Y.; Hagihara, N. Tetrahedron lett. 1975, 16, 4467. For selected reviews, see: (b) Chinchilla, R.; Najera, C. Chem. Soc. Rev. 2011, 40, 5084. (c) Negishi , E.-i.; Anastasia, L. Chem. Rev. 2003, 103, 1979. (d) Sonogashira, K. J. Organomet. Chem. 2002, 653, 46. Recently, Tanabe and co-workers succeeded in conducting the Sonogashira coupling of $\beta$-ketoester enol tosylates under mild conditions: (e) Nakatsuji, H.; Ueno, K.; Misaki, T.; Tanabe, Y. Org. Lett. 2008, 10, 2131. For an example of Sonogashira-type coupling of aryl tosylates, see: (f) Gelman, D.; Buchwald, S. L. Angew. Chem. Int. Ed. 2003, 42, 5993.

(8) For other approaches toward fluorinated enynes, see: (a) Ichitsuka, T.; Takanohashi, T.; Fujita, T.; Ichikawa, J. J. Fluorine 
Chem. 2015, 170, 29. (b) Zhang, Z.; Zhou, Q.; Yu, W.; Li, T.; Wu, G.; Zhang, Y.; Wang, J. Org. Lett. 2015, 17, 2474. (c) Chen, S.; Xu, C.; Lu, L.; Shen, Q. Chin. J. Chem. 2013, 31, 901.

(9) (a) Moon, J.; Jeong, M.; Nam, H.; Ju, J.; Moon, J. H.; Jung, H. M.; Lee, S. Org. Lett. 2008, 10, 945. (b) Kim, H.; Lee, P. H. Adv. Synth. Catal. 2009, 351, 2827. (c) Moon, J.; Jang, M.; Lee, S. J. Org. Chem. 2009, 74, 1403.

(10) For the earliest example, see: (a) Ueura, K.; Satoh, T.; Miura, M. Org. Lett. 2007, 9, 1407.

(11) For selected recent reviews for $\mathrm{C}-\mathrm{H}$ functionalization, see: (a) Boyarskiy, V. P.; Ryabukhin, D. S.; Bokach, N. A.; Vasilyev, A. V. Chem. Rev. 2016, 116, 5894. (b) Gulías, M.; Mascareñas, J. L. Angew. Chem., Int. Ed. 2016, 55, 11000. (c) Chen, Z.; Wang, B.; Zhang, J.; Yu, W.; Liu, Z.; Zhang, Y. Org. Chem. Front. 2015, 2, 1107. (d) Song, G.; Li, X. Acc. Chem. Res. 2015, 48, 1007. (e) Miura, M.; Satoh, T.; Hirano, K. Bull. Chem. Soc. Jpn. 2014, 87, 751. (f) Jin, T.; Zhao, J.; Asao, N.; Yamamoto, Y. Chem.-Eur. J. 2014, 20 , 3554. (g) De Sarkar, S.; Liu, W.; Kozhushkov, S. I.; Ackermann, L. Adv. Synth. Catal. 2014, 356, 1461. (h) Kuhl, N.; Schröder, N.; Glorius, F. Adv. Synth. Catal. 2014, 356, 1443. (i) Shi, G.; Zhang, Y. Adv. Synth. Catal. 2014, 356, 1419. (j) Bonin, H.; Sauthier, M.; Felpin, F.-X. Adv. Synth. Catal. 2014, 356, 645. (k) Engle, K. M.; Yu, J.-Q. J. Org. Chem. 2013, 78, 8927. (1) Wencel-Delord, J.; Glorius, F. Nat. Chem. 2013, 5, 369. (m) Colby, D. A.; Tsai, A. S.; Bergman, R. G.; Ellman, J. A. Acc. Chem. Res. 2012, 45, 814. (n) Engle, K. M.; Mei, T.-S.; Wasa, M.; Yu, J.-Q. Acc. Chem. Res. 2012, 45, 788. (o) Mitchell, E. A.; Peschiulli, A.; Lefevre, N.; Meerpoel, L.; Maes, B. U. W. Chem. Eur. J. 2012, 18, 10092. (p) Cho, S. H.; Kim, J. Y.; Kwak, J.; Chang, S. Chem. Soc. Rev. 2011, 40, 5068. (q) Wencel-Delord, J.; Droge, T.; Liu, F.; Glorius, F. Chem. Soc. Rev. 2011, 40, 4740. (r) Kuninobu, Y.; Takai, K. Chem. Rev. 2011, 111, 1938. (s) Liu, C.; Zhang, H.; Shi, W.; Lei, A. Chem. Rev. 2011, 111, 1780. (t) Ackermann, L. Chem. Rev. 2011, 111, 1315. (u) Lapointe, D.; Fagnou, K. Chem. Lett. 2010, 39, 1118. (v) Lyons, T. W.; Sanford, M. S. Chem. Rev. 2010, 110, 1147. (w) Colby, D. A.; Bergman, R. G.; Ellman, J. A. Chem. Rev. 2010, 110, 624. (x) Sun, C.-L.; Li, B.-J.; Shi, Z.-J. Chem. Commun. 2010, 46, 677. (y) Satoh, T.; Miura, M. Chem.-Eur. J. 2010, 16, 11212. (z) Satoh, T.; Miura, M. Synthesis 2010, 3395. (aa) Chen, X.; Engle, K. M.; Wang, D.-H.; Yu, J.Q. Angew. Chem., Int. Ed. 2009, 48, 5094. (bb) Daugulis, O.; Do, H.-Q.; Shabashov, D. Acc. Chem. Res. 2009, 42, 1074. (cc) McGlacken, G. P.; Bateman, L. M. Chem. Soc. Rev. 2009, 38, 2447. (dd) Li, C.-J. Acc. Chem. Res. 2009, 42, 335. (ee) Kakiuchi, F.; Kochi, T. Synthesis 2008, 3013.

(12) D. R. Stuart, M. Bertrand-Laperle, K. M. N. Burgess, K. Fagnou, J. Am. Chem. Soc. 2008, 130, 16474.

(13) Qiao, Y.; Si, T.; Yang, M.-H.; Altman, R. A. J. Org. Chem. 2014, 79, 7122 .

(14) For example, see: (a) Rueeger, H.; Lueoend, R.; Rogel, O.; Rondeau, J. M.; Mobitz, H.; Machauer, R.; Jacobson, L.; Staufenbiel, M.; Desrayaud, S.; Neumann, U. J. Med. Chem. 2012, 55, 3364. (b) Hall, A.; Billinton, A.; Brown, S. H.; Chowdhury, A.; Giblin, G. M. P.; Goldsmith, P.; Hurst, D. N.; Naylor, A.; Patel, S.; Scoccitti, T.; Theobald, P. J. Bioorg. Med. Chem. Lett. 2008, 18, 2684.

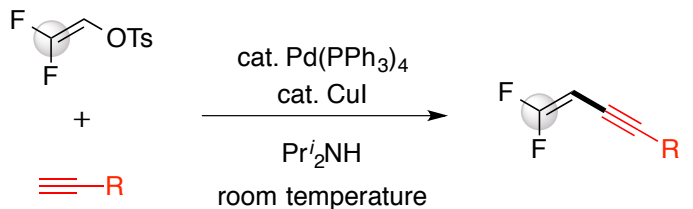

